\title{
Aetiology and Epidemiology of Maxillofacial Injuries during the Stay-At-Home Period Due To the COVID-19 Pandemic: a Single Center Study
}

\author{
Pooja Gangwani' ${ }^{1}$ Haley Harris ${ }^{1}$, Molly Christie${ }^{1}$, Kyle Mecca ${ }^{1}$, Basir Barmak ${ }^{2}$, Antonia \\ Kolokythas ${ }^{1}$
}

${ }^{1}$ Department of Oral and Maxillofacial Surgery, University of Rochester, Eastman Institute for Oral Health, Rochester, New York, United States.

${ }^{2}$ Department of Clinical Research and Biostatistics, University of Rochester, Eastman Institute for Oral Health, Rochester, New York, United States.

\author{
Corresponding Author: \\ Pooja Gangwani \\ Department of Oral and Maxillofacial Surgery \\ University of Rochester, Strong Memorial Hospital-EIOH \\ 601 Elmwood Avenue, AC-4, Box 705, Rochester NY 14642 \\ United States \\ Phone: 585-276-6606 \\ Fax: 585-276-1883 \\ E-mail: pooja_gangwani@urmc.rochester.edu
}

\begin{abstract}
Objectives: The aim of this retrospective comparative study was to evaluate the effects of implemented social and public health measures during the COVID-19 pandemic on the incidence and aetiology of maxillofacial injuries.

Material and Methods: A retrospective chart review of all the patients who had sustained maxillofacial injuries and presented to the emergency department of Strong Memorial Hospital between March 20 $0^{\text {th }}$ and June $24^{\text {th }}, 2019$ and 2020, were included in our study. The total study sample comprised of 335 patients ( $n=140$ in 2019 group, $n=195$ in 2020 group). The primary outcome variables of the study were the number of cases and aetiology of maxillofacial injuries. Statistical analysis consisted of descriptive statistics, Chi-square, and two sample t-tests.

Results: The number of patients in the 2020 group was higher $(n=195)$ than the number of patients in the 2019 group $(n=$ 140). Comparatively, there was an increase in the maxillofacial injuries during the stay-at-home period by $(\mathrm{n}=55[39.29 \%])$. Although not statistically significant, the aetiology of injuries differed during the stay-at-home period compared to the normal times.

Conclusions: The number of maxillofacial injuries increased during the period of implemented social and public health measures during the early months of the COVID-19 pandemic. Such knowledge can provide valuable information for the establishment of prevention programs and effective health policies and help in the decision-making process pertaining to resource allocation in a dire situation of the pandemic.
\end{abstract}

Keywords: COVID-19; epidemiology; maxillofacial injuries; pandemics.

Accepted for publication: 22 December 2021

To cite this article:

Gangwani P, Harris H, Christie M, Mecca K, Barmak B, Kolokythas A.

Aetiology and Epidemiology of Maxillofacial Injuries during the Stay-At-Home Period Due To the COVID-19 Pandemic: a Single Center Study

J Oral Maxillofac Res 2021;12(4):e4

URL: http://www.ejomr.org/JOMR/archives/2021/4/e4/v12n4e4.pdf

doi: $10.5037 /$ jomr.2021.12404 


\section{INTRODUCTION}

The current pandemic caused by the novel severe acute respiratory syndrome coronavirus 2 (SARSCoV-2) has claimed the lives of more than 5 million people worldwide [1]. The first confirmed case of coronavirus disease 2019 (COVID-19) in the United States was reported in the state of Washington on January 20, 2020 [2]. Since then, the virus has spread across the country. The pandemic arrived in the state of New York in late February 2020, with the first confirmed case on March 1, 2020 [3]]. In order to increase the overall hospital beds, preserve and re-allocate personal protective equipment (PPE), all hospitals in the state of New York postponed elective surgeries. Furthermore, to mitigate the spread of COVID-19, the "New York State on PAUSE" executive order was placed by the state government on March 20, 2020 [4]. The executive order entailed employing social distancing measures, maximizing opportunities to work from home, and avoiding local travel. This led to the closure of schools, restrictions on non-essential work, travel, and sport activities, leaving most of the people confined to their homes.

Studies have shown that human lifestyles, social behaviour, and environmental factors influence the epidemiology and aetiology of trauma $[\underline{5}, \underline{6}]$. Thus, it is safe to assume that this unprecedented public health emergency may have altered factors that influence the epidemiology of maxillofacial trauma. An epidemiological appraisal is vital to analyse the change in patterns and new trends pertaining to the demographics and aetiology of maxillofacial trauma. Additionally, it can also help in developing effective health policies and establishment of prevention programs to prevent facial trauma and injuries, particularly in the most vulnerable population $[\underline{5}, \underline{6}]$.

Several studies have reported the impact of enforcement of "stay at home" orders on maxillofacial injuries [7-10]. The authors have concluded a decrease in the overall number of maxillofacial trauma patients presenting to their medical centers. The majority of those studies were conducted in urban areas. Little is known regarding the impact of social distancing on maxillofacial injuries in suburban regions. Therefore, we propose to perform a comparative retrospective chart analysis of facial trauma patients who presented to the emergency room of Strong Memorial Hospital (SMH), Rochester, New York, during the "stay at home" period from March $20^{\text {th }}$ through June 24, 2020 to those of normal times of March $20^{\text {th }}$ through June $24^{\text {th }}, 2019$. The aim of this study is to evaluate the effects of implemented social and public health measures during the COVID-19 pandemic on the incidence and aetiology of maxillofacial injuries.

The authors hypothesized that the aetiology of maxillofacial injuries would differ during the COVID-19 pandemic as compared to the normal times. The authors also hypothesized that the incidence of facial trauma would decrease due to stayat-home order, work from home, and social distancing measures implemented by state governments during the COVID-19 pandemic.

\section{MATERIAL AND METHODS}

This study was approved by the University of Rochester's Research Subjects Review Board (STUDY00005288). A retrospective chart review of all the patients who had sustained maxillofacial trauma and presented to the emergency department of SMH between March $20^{\text {th }}$ and June $24^{\text {th }}, 2019$ and 2020 were included in our study. SMH is the region's only level one trauma center. Oral and maxillofacial surgery, plastic and reconstructive surgery, and otolaryngology services manage maxillofacial injuries at SMH. Patients treated by all three services are included in the trauma registry.

To identify study patients, we accessed the SMH trauma registry, which includes patients who have at least one of the following injury diagnostic codes defined by the International Classification of Diseases, Tenth Revision (ICD-10-CM): S00-S99 with $7^{\text {th }}$ character modifiers of $\mathrm{A}, \mathrm{B}$, or $\mathrm{C}$ only (injuries to specific body parts-initial encounter); T07 (unspecified multiple injuries); T14 (injury of unspecified body region); T79.A1-T79.A9 with $7^{\text {th }}$ character modifier of A only (traumatic compartment syndrome-initial encounter). In addition to the abovementioned criteria, the SMH trauma registry also includes patients who required level 1 activation, level 2 activation, or trauma surgery consult upon arrival to the Emergency Department.

The trauma registry was searched manually for all patients who sustained facial injuries (fractures and/ or lacerations) in the head and neck region between March 20 th and June 24 $4^{\text {th }}, 2019$ and 2020. Patients with incomplete records were excluded from the study. Patients who presented with a complication of facial fractures and lacerations, as a subsequent encounter were not included in our study sample. Similarly, patients who were seen after already having received treatment either for a second opinion or to establish continued care close to their home, were not admitted into our study. 
Patients were divided into two groups: normal times - "2019 group" and stay at home "2020 group". Data were extracted on the following variables: age at the time of injury, gender, race, and aetiology, types of maxillofacial trauma, concomitant injuries, and ethanol test results. Due to several inconsistencies in the recording of the drug toxicology screens upon admission, this variable was not included in our study. Radiology reports and computed tomography maxillofacial scans were used to diagnose and document facial fractures. Clinical records and/or photographs were reviewed to confirm the presence of head and neck lacerations. To document data on concomitant injures, emergency room admission records, trauma history and physical notes, and notes from specialty consultation services such as neurosurgery, orthopaedics were accessed.

The primary outcome variables of the study were the number of cases and aetiology of maxillofacial trauma. Information on aetiology was reported under the following groups: assault, all-terrain vehicle (ATV) accident, bicycle accident, child abuse, dog bites, fall, motorcycle accident, motor vehicle collision (MVC), pedestrian struck, sports-related, suicide attempt, and work-related. Demographic variables included age at the time of injury, gender, race. Based on the available information, the race was categorized as Caucasian, African American, Asian, other, and not documented.

Other study variables included types of maxillofacial trauma, concomitant injuries (polytrauma), and ethanol test results. Details of maxillofacial trauma were documented under the following categories: skull, frontal sinus, nasal, orbit, zygoma/maxilla, and mandible. Furthermore, a note of the presence of lacerations (scalp, face, neck, intraoral) was made. Data on concomitant injuries were investigated as well. The injuries were classified under the following categories: intracranial haemorrhage, rib fractures, abdominal injuries, orthopaedic fractures. To calculate the mean score, each of the aforementioned categories was given a score of one point. Ethanol test results were reported as positive, negative, and not collected.

\section{Statistical analysis}

The data on the above-mentioned variables were entered in Microsoft Office Excel 2019 program (Microsoft Corporation; Washington, USA) by three resident investigators ( $\mathrm{HH}, \mathrm{MC}$, and $\mathrm{KM}$ ) and were verified by the faculty investigator (PG) for accuracy. The data was then imported to Minitab ${ }^{\circledR}$ version 19.2020.1 (Minitab LLC.; State College, Pennsylvania, USA) for data analysis. Descriptive statistics, Chi-square, and two sample t-tests were performed. Statistical significance was defined as P-value $<0.05$. Parametric data were expressed as mean and standard deviation (M [SD]).

\section{RESULTS}

The study sample comprised of 335 patients who presented to Strong Memorial Hospital for evaluation and management of maxillofacial injuries between March 20 $0^{\text {th }}$ and June 24 ${ }^{\text {th }}, 2019$ and 2020. The demographics of the patients treated between March $20^{\text {th }}$ and June $24^{\text {th }}, 2019$ and 2020 are summarized in Table 1. Of 195 patients in group 2020, 149 were male $(76.41 \%)$ and 46 were female $(23.59 \%)$.

Table 1. Demographic characteristics of study population

\begin{tabular}{|c|c|c|c|c|c|c|c|}
\hline & \multirow{2}{*}{\multicolumn{2}{|c|}{ Variables }} & \multirow{2}{*}{\multicolumn{2}{|c|}{$\begin{array}{c}2019 \operatorname{group}(n=140) \\
\text { N }(\%)\end{array}$}} & \multirow{2}{*}{\multicolumn{2}{|c|}{$\frac{2020 \operatorname{group}(n=195)}{\text { N }(\%)}$}} & \multirow{2}{*}{ P-value } \\
\hline & & & & & & & \\
\hline \multirow{2}{*}{ Gender } & \multicolumn{2}{|l|}{ Female } & \multicolumn{2}{|c|}{$51(36.43 \%)$} & \multicolumn{2}{|c|}{$46(23.59 \%)$} & \multirow{2}{*}{$0.011^{\mathrm{a}}$} \\
\hline & \multicolumn{2}{|l|}{ Male } & \multicolumn{2}{|c|}{$89(63.57 \%)$} & \multicolumn{2}{|c|}{$149(76.41 \%)$} & \\
\hline \multirow{4}{*}{ Age (years) } & \multicolumn{2}{|l|}{$<18$} & \multicolumn{2}{|c|}{$16(11.43 \%)$} & \multicolumn{2}{|c|}{$20(10.26 \%)$} & \multirow{4}{*}{0.984} \\
\hline & \multicolumn{2}{|l|}{$18-34.99$} & \multicolumn{2}{|c|}{$39(27.86 \%)$} & \multicolumn{2}{|c|}{$57(29.23 \%)$} & \\
\hline & \multicolumn{2}{|l|}{$35-64.99$} & \multicolumn{2}{|c|}{$57(40.71 \%)$} & \multicolumn{2}{|c|}{$79(40.51 \%)$} & \\
\hline & \multicolumn{2}{|l|}{$>65$} & \multicolumn{2}{|c|}{$28(20 \%)$} & \multicolumn{2}{|c|}{$39(20 \%)$} & \\
\hline \multirow{5}{*}{ Race } & \multicolumn{2}{|l|}{ Caucasian } & \multicolumn{2}{|c|}{$103(73.57 \%)$} & \multicolumn{2}{|c|}{$132(67.69 \%)$} & \multirow{5}{*}{0.394} \\
\hline & \multicolumn{2}{|c|}{ African American } & \multicolumn{2}{|c|}{$27(19.29 \%)$} & \multicolumn{2}{|c|}{$50(25.64 \%)$} & \\
\hline & \multirow{3}{*}{ Miscellaneous } & Asian & \multirow{3}{*}{$10(7.13 \%)$} & $1(0.71 \%)$ & \multirow{3}{*}{$13(6.67 \%)$} & $2(1.03 \%)$ & \\
\hline & & Not documented & & $1(0.71 \%)$ & & $4(2.05 \%)$ & \\
\hline & & Other & & $8(5.71 \%)$ & & $7(3.59 \%)$ & \\
\hline
\end{tabular}

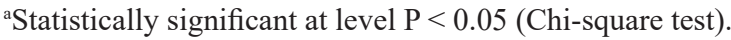
$\mathrm{N}=$ number of patients. 
Of 140 patients in the group 2019, 89 were male $(63.57 \%)$ and 51 were female $(36.43 \%)$. The mean age of patients in group 2020 and 2019 was 43.74 and 45.22 years, respectively. The two major racial groups involved in the study were Caucasians and African Americans, with 132 (67.69\%) Caucasians in 2020 and $103(73.57 \%)$ in 2019, compared to $50(25.64 \%)$ African Americans in 2020 and 27 (19.29\%) in 2019.

The number of patients in the "group 2020" were higher $(\mathrm{n}=195)$ than the number of patients in the "group 2019" ( $\mathrm{n}=140)$. Comparatively, there was an increase in the maxillofacial injuries during the stay-at-home period by $39.29 \%$. The aetiology of maxillofacial injuries between March $20^{\text {th }}$ and
June $24^{\text {th }}, 2019$ and 2020 are summarized in Table 2. The three most common causes of maxillofacial trauma across 2020 and 2019 groups were fall, assault, and motor vehicle collision. Other aetiology included pedestrian struck by a vehicle, motorcycle, bicycle, and ATV accidents, suicide attempts, sports, and work-related trauma, child abuse, and dog bites.

The patterns of maxillofacial trauma cases and associated concomitant injuries between March $20^{\text {th }}$ and June $24^{\text {th }}, 2019$ and 2020 are summarized in Table 3. The three most common types of facial fractures across 2020 and 2019 groups were nasal, orbit, and maxilla/zygoma. Other types of facial fractures included skull, mandible, and frontal sinus.

Table 2. Aetiology pertaining to maxillofacial injuries

\begin{tabular}{|c|c|c|c|c|c|c|}
\hline \multirow{2}{*}{\multicolumn{2}{|c|}{ Variables }} & \multirow{2}{*}{\multicolumn{2}{|c|}{$\begin{array}{c}2019 \text { group }(n=140) \\
\text { N }(\%)\end{array}$}} & \multirow{2}{*}{\multicolumn{2}{|c|}{$\begin{array}{c}2020 \operatorname{group}(n=195) \\
\text { N }(\%)\end{array}$}} & \multirow{2}{*}{ P-value } \\
\hline & & & & & & \\
\hline \multicolumn{7}{|c|}{ Aetiology of maxillofacial trauma } \\
\hline \multicolumn{2}{|c|}{ Assault } & \multicolumn{2}{|c|}{$30(21.43 \%)$} & \multicolumn{2}{|c|}{$45(23.08 \%)$} & \multirow{12}{*}{$0.861^{\mathrm{a}}$} \\
\hline \multicolumn{2}{|c|}{ ATV + bicycle accident } & \multicolumn{2}{|c|}{$8(5.72 \%)$} & \multicolumn{2}{|c|}{$18(9.23 \%)$} & \\
\hline \multicolumn{2}{|c|}{ Suicide attempt } & \multicolumn{2}{|c|}{$5(3.57 \%)$} & \multicolumn{2}{|c|}{$10(5.13 \%)$} & \\
\hline \multicolumn{2}{|c|}{ Pedestrian struck } & \multicolumn{2}{|c|}{$8(5.71 \%)$} & \multicolumn{2}{|c|}{$10(5.13 \%)$} & \\
\hline \multicolumn{2}{|c|}{ Fall } & \multicolumn{2}{|c|}{$43(30.71 \%)$} & \multicolumn{2}{|c|}{$58(29.74 \%)$} & \\
\hline \multicolumn{2}{|c|}{ Motorcycle accident } & \multicolumn{2}{|c|}{$8(5.71 \%)$} & \multicolumn{2}{|c|}{$8(4.1 \%)$} & \\
\hline \multicolumn{2}{|c|}{ Motor vehicle collision } & \multicolumn{2}{|c|}{$22(15.71 \%)$} & \multicolumn{2}{|c|}{$30(15.38 \%)$} & \\
\hline \multirow{5}{*}{ Miscellaneous } & Work related & \multirow{5}{*}{$16(11.43 \%)$} & $4(2.86 \%)$ & \multirow{5}{*}{$16(8.21 \%)$} & $6(3.08 \%)$ & \\
\hline & $\begin{array}{l}\text { Sports } \\
\text { related }\end{array}$ & & $7(5 \%)$ & & $2(1.03 \%)$ & \\
\hline & Child abuse & & 0 & & $1(0.51 \%)$ & \\
\hline & Dog bite & & $2(1.43 \%)$ & & $3(1.54 \%)$ & \\
\hline & Other & & $3(2.14 \%)$ & & $4(2.05 \%)$ & \\
\hline
\end{tabular}

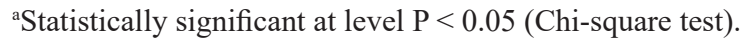

$\mathrm{N}=$ number of patients; ATV $=$ all-terrain vehicle.

Table 3. Characteristics of maxillofacial injuries and polytrauma

\begin{tabular}{|c|c|c|c|}
\hline \multirow{2}{*}{ Variables } & 2019 group $(n=131)$ & 2020 group $(n=167)$ & \multirow{2}{*}{ P-value } \\
\hline & $\mathbf{N}$ & $\mathbf{N}$ & \\
\hline \multicolumn{4}{|l|}{ Injuries } \\
\hline \multicolumn{4}{|l|}{ Facial fractures } \\
\hline Nasal & 30 & 40 & \multirow{6}{*}{0.897} \\
\hline Orbit & 28 & 40 & \\
\hline Maxilla/zygoma & 28 & 39 & \\
\hline Skull & 24 & 27 & \\
\hline Mandible & 13 & 15 & \\
\hline Frontal & 8 & 6 & \\
\hline Facial fractures & 4.54 (SD 9.58) & $3.82(\mathrm{SD} 7.54)$ & 0.6 \\
\hline \multicolumn{4}{|l|}{ Lacerations } \\
\hline Scalp, face, neck, intraoral & $1.2(\mathrm{SD} 0.4)$ & $1.06(\mathrm{SD} 0.24)$ & $0.002^{\mathrm{a}}$ \\
\hline \multicolumn{4}{|l|}{ Polytrauma } \\
\hline $\begin{array}{l}\text { Intracranial haemorrhage, rib fractures, } \\
\text { abdominal injuries, orthopaedic fractures }\end{array}$ & $1.55(\mathrm{SD} 0.72)$ & $1.46(\mathrm{SD} 0.71)$ & 0.386 \\
\hline
\end{tabular}

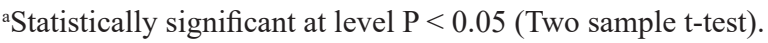

$\mathrm{N}=$ number of patients; $\mathrm{SD}=$ standard deviation . 
No statistical difference was noted pertaining to the types of maxillofacial fractures (P-value of 0.897) and the number of facial fractures across 2020 and 2019 groups (3.82 [SD 7.54] and 4.54 [SD 9.58]), respectively, with a P-value of 0.6. A significant number of patients sustained scalp, facial, neck, and intraoral lacerations across both groups. Statistical difference was found with respect to the presence of lacerations using a two-sample t-test across the 2020 and 2019 groups. The mean score of lacerations in group 2020 was lower (1.06 [SD 0.24]) than in group 2019 (1.2 [SD 0.4], P-value 0.002). In relation to concomitant injuries (polytrauma), no statistical difference was noted using a two-sample t-test across the 2020 and 2019 groups. The mean score of polytrauma in group 2020 was 1.46 (SD 0.71) and in group 2019 was 1.55 (SD 0.72), with P-value of 0.386. Of 335 patients, blood alcohol level was measured on 222 patients. As noted in Table 4 more patients presented with a positive alcohol level in the 2020 group compared to the 2019 group (43.18\% in 2020 vs. $34.44 \%$ in 2019 , P-value 0.191 ). Table 5 reveals the relationship between aetiologies of facial trauma in patients with positive alcohol levels across both groups.

\section{DISCUSSION}

The effects of maxillofacial trauma are significant. Many patients undergo hospital admission, surgical management, and in some cases rehabilitation, placing an immense burden on the hospital and health care systems. Therefore, understanding the epidemiology of facial trauma is crucial. Data collection on epidemiology aids in establishing health care policies related to the development of preventive measures. This comparative retrospective study aimed to evaluate the effects of implemented social and public
Table 4. Relationship between alcohol and maxillofacial injuries

\begin{tabular}{l|c|c|c}
\hline & 2019 group $(\mathbf{n}=\mathbf{9 0})$ & 2020 group $(\mathbf{n}=\mathbf{1 3 2})$ & \multirow{2}{*}{ P-value } \\
\cline { 2 - 3 } & $\mathbf{N ~ ( \% )}$ & $\mathbf{N ~ ( \% )}$ & \\
\hline $\begin{array}{l}\text { Alcohol } \\
\text { positive }\end{array}$ & $31(34.44 \%)$ & $57(43.18 \%)$ & \multirow{2}{*}{$0.191^{\mathrm{a}}$} \\
\hline $\begin{array}{l}\text { Alcohol } \\
\text { negative }\end{array}$ & $59(65.56 \%)$ & $75(56.82 \%)$ & \\
\hline
\end{tabular}

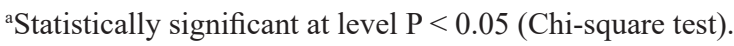

$\mathrm{N}=$ number of patients.

health measures during the COVID-19 pandemic on the incidence and aetiology of maxillofacial injuries.

Our study found that the number of patients in the 2020 group were higher $(n=195)$ than the number of patients in the 2019 group $(n=140)$. Comparatively, there was an increase in the maxillofacial trauma cases during the stay-at-home period by $(\mathrm{n}=55$ $[39.29 \%])$. This was an unexpected finding. Our study findings differ from the results of other studies that have explored the impact of social distancing on maxillofacial trauma. A retrospective cohort study by Ludwig et al. [7] revealed a decreased number of patients presenting with oral and maxillofacial fractures during the period of social distancing ( $\mathrm{n}=235$ in 2020) compared to normal times ( $\mathrm{n}=330$ in 2018; $\mathrm{n}=318$ in 2019), at their Level I trauma center in Seattle, Washington [7]. Similarly, another retrospective cohort study by Press [ [ $]$ showed a $35.6 \%$ reduction in trauma patients during the lockdown period at Level II trauma center in Nashville, Tennessee [ㅇ]. Salzano et al. [9] in their Italian multi-center study reported a reduction of $69.1 \%$ in the number of patients requiring the management of facial fractures compared to the previous year. To study the impact of the COVID-19 lockdown on the epidemiology of maxillofacial trauma activity, de Boutray et al. [10] conducted a retrospective multi-center study in France. They noted a reduction in maxillofacial trauma activity by $65.5 \%$.

Table 5. Relationship between aetiology of facial trauma in patients with positive alcohol level across both groups

\begin{tabular}{|c|c|c|c|c|c|c|}
\hline \multirow{2}{*}{\multicolumn{2}{|c|}{ Variables }} & \multirow{2}{*}{\multicolumn{2}{|c|}{$\begin{array}{c}2019 \text { group }(n=31) \\
\text { N }(\%)\end{array}$}} & \multirow{2}{*}{\multicolumn{2}{|c|}{$\begin{array}{c}2020 \text { group }(n=57) \\
\text { N }(\%)\end{array}$}} & \multirow{2}{*}{ P-value } \\
\hline & & & & & & \\
\hline \multicolumn{7}{|c|}{ Aetiology of maxillofacial trauma } \\
\hline \multicolumn{2}{|c|}{ Assault } & \multicolumn{2}{|c|}{$15(48.39 \%)$} & \multicolumn{2}{|c|}{$19(33.33 \%)$} & \\
\hline \multicolumn{2}{|c|}{ ATV + bicycle + motorcycle accident } & \multicolumn{2}{|c|}{$3(9.69 \%)$} & \multicolumn{2}{|c|}{$3(5.26 \%)$} & \\
\hline \multicolumn{2}{|c|}{ Fall } & \multicolumn{2}{|c|}{$6(19.35 \%)$} & \multicolumn{2}{|c|}{$16(28.07 \%)$} & \\
\hline \multicolumn{2}{|c|}{ Motor vehicle collision } & \multicolumn{2}{|c|}{$4(12.9 \%)$} & \multicolumn{2}{|c|}{$15(26.32 \%)$} & $0.378^{\mathrm{a}}$ \\
\hline \multirow{3}{*}{ Other } & Other & \multirow{3}{*}{$3(9.68 \%)$} & 0 & \multirow{3}{*}{$4(7.01 \%)$} & $1(1.75 \%)$ & \\
\hline & Pedestrian struck & & $2(6.45 \%)$ & & $2(3.51 \%)$ & \\
\hline & Suicide attempt & & $1(3.23 \%)$ & & $1(1.75 \%)$ & \\
\hline
\end{tabular}

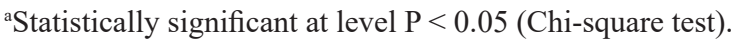

$\mathrm{N}=$ number of patients; ATV = all-terrain vehicle. 
We believe increased consumption of alcohol in the 2020 group contributed to the rise in maxillofacial injuries in our region. A combination of social isolation, financial hardships from the loss of employment, and anxiety due to an uncertain future have led to an increasing trend in alcohol use during the COVID-19 pandemic [11,12]. In our study, more patients presented with a positive alcohol level in the 2020 group compared to the 2019 group (43.18\% in 2020 vs. $\% 34.44 \%$ in 2019 , P-value 0.19 ). Within the alcohol-positive group, injuries due to MVC doubled in 2020 compared to 2019 (26.32\% in 2020 vs. $12.90 \%$ in 2019). More patients presented secondary to fall in 2020 compared to 2019 (28.07\% in 2020 vs. $19.35 \%$ in 2019).

Studies have documented adverse public health effects of economic crises and rises in unemployment [13]. Furthermore, there is a direct correlation between social isolation and loneliness, and mental health disorders including anxiety and depression, leading to suicide attempts $[\underline{14}, \underline{15}]$. Therefore, it was anticipated that number of interpersonal assaults, and suicide attempts would increase during the COVID-19 pandemic. Although not statistically significant, our study noted a slight increase in interpersonal assault $(\mathrm{n}=45$ [23.08\%]) and suicide attempt (n $=10[5.13 \%])$ in the 2020 group compared to the 2019 group (assault: $\mathrm{n}=30$ [21.43\%] and suicide: $\mathrm{n}=5[3.57 \%])$. Under the category of assault, we closely looked at the data of gun shot and stab wounds. A slight increase was observed in the 2020 group concerning gun shots $(\mathrm{n}=7)$ and stab wounds $(\mathrm{n}=16)$ relative to 2019 group (gun shots: $\mathrm{n}=3$ and stab wounds: $n=10$ ). In the study by Ludwig et al. [7], the authors noted a statistical increase in facial injuries from assault in the $2020(21 \%$ in 2020) group compared to the $18 \%$ in 2018 and $15 \%$ in 2019 groups. They also recorded more cases of gun violence in the 2020 group (7\%) as compared to 2018 (3\%) and 2019 (3\%) groups. Olding et al. [16] performed a study in South London, U.K., on penetrating trauma during COVID-19. They concluded that while their overall trauma cases decreased by $35 \%$ compared to the previous year, there was a significant increase in injuries related to self-harm [16]. A comparative, retrospective study conducted by Vishal et al. [17] in India documented a $50 \%$ increase in trauma cases due to assault compared to the previous year.

Given the public's adherence to stay-at-home order, work from home, and COVID-19 restrictions, it was assumed that number of MVCs, ATVs, and motorcycle accidents would decrease in our region. Several studies have reported a marked reduction in road traffic collisions. $[10,17,18]$. However, this was not observed in our study. One of the probable explanations for this unusual finding could be tied to the positivity rate in our region (Finger Lakes Region). At the time of "New York State on PAUSE", New York City was the epicenter of COVID-19 in the state of New York, with its positivity rate being $57.4 \%, 8.5 \%$, and $1.3 \%$ in the months of April, May, June 2020, respectively [19]. The positivity rate of COVID-19 in our region in the months of April $(13.3 \%)$, May $(4.3 \%)$, and June $(0.8 \%)$ was lower than the rest of the state of New York (April: 48.1\%, May: 5.9\%, and June 1.1\%) [19]. We believe that the lower positivity rate in combination with pandemic fatigue and improved weather conditions in upstate NY led to an almost similar number of MVCs in 2020 compared with 2019.

An interesting finding of our study is the change in the number of bicycle accidents and sportsrelated injuries. In 2020, the number of bicycle and ATV accidents $(\mathrm{n}=18$ [9.23\%]) increased, and sports-related injuries decreased $(n=2[1.03 \%])$ in comparison with 2019 (bicycle + ATV: $\mathrm{n}=8[5.72 \%]$; sports: $\mathrm{n}=7[5 \%])$. This finding was contrary to the results by Chiba et al. [20], who reported their bicycle injury admissions reduced by $28.4 \%$ at a large urban trauma center in California. Our trauma center is located in a suburban region, where the population density is lower than in urban areas. While avoiding group sports, riding outside to keep up with exercise and fitness was perceived safe by many people and may potentially explain the observed finding.

The major strength of our study is that all patients who presented to SMH with maxillofacial injuries were included regardless of the surgical service involved in the patient's care. The trauma registry at SMH is robust and very detailed; thus, we are confident that the data is accurate and inclusive. The major limitation of this study is its retrospective nature. Also, the study was performed at a single center of a suburban region in the state of New York. It is unclear whether geographical location and weather conditions were the confounding factors in understanding the impact of social distancing on the aetiology of maxillofacial trauma. Nationwide studies at urban, suburban, and rural trauma centers are required to draw generalizable results pertaining to the impact of social distancing on maxillofacial trauma.

Furthermore, the study was conducted over a short period of time. A study covering the entire duration of the pandemic may provide a better insight into the epidemiology of facial trauma. 
A year-long study will permit comparison between the two cohorts (pre-pandemic versus post-pandemic) in a geographic location with respect to seasonal variation.

Despite the limitations to this study, it is still valuable to understand the complex interplay of social distancing, geographical location, number of COVID-19 cases in the region of interest, social behaviour, environmental factors, and its impact on maxillofacial injuries. Recognizing that in certain areas of the state or nation, there is no direct corelation between social distancing and decrease in trauma cases presenting to the emergency room is crucial. Several factors play a role in social behaviour adapted by people, which could either increase or decrease the incidence of trauma, and more importantly, change the patterns of aetiology. All of this information is necessary to make decisions related to the allocation of health care resources. Additionally, it can also help develop effective health policies, and establish prevention programs to prevent facial trauma and injuries, particularly in the most vulnerable population.

\section{CONCLUSIONS}

The incidence of maxillofacial injuries in our region increased during the stay-at-home period. Although not statistically significant, the aetiology of injuries differed during the stay-at-home period compared to the normal times. Analysing the effects of social distancing, health, and financial burdens on the epidemiology of maxillofacial trauma is essential. Such knowledge can provide valuable information for the establishment of prevention programs and effective health policies and help in decision-making process pertaining to resource allocation in a dire situation of the pandemic.

\section{ACKNOWLEDGMENTS AND DISCLOSURE STATEMENTS}

We would like to thank Kate Dellonte, Performance Improvement Coordinator \& Quality Assurance Liaison, University of Rochester - Kessler Trauma Center, for helping us access the data from the Trauma Registry.

\section{REFERENCES}

1. Johns Hopkins Coronavirus Resource Center. Global Deaths. [URL: https://coronavirus.jhu.edu/]

2. Holshue ML, DeBolt C, Lindquist S, Lofy KH, Wiesman J, Bruce H, Spitters C, Ericson K, Wilkerson S, Tural A, Diaz G, Cohn A, Fox L, Patel A, Gerber SI, Kim L, Tong S, Lu X, Lindstrom S, Pallansch MA, Weldon WC, Biggs HM, Uyeki TM, Pillai SK; Washington State 2019-nCoV Case Investigation Team. First Case of 2019 Novel Coronavirus in the United States. N Engl J Med. 2020 Mar 5;382(10):929-936. [Medline: 32004427] [PMC free article: 7092802] [doi: 10.1056/NEJMoa2001191]

3. Goldstein J, McKinley J. Coronavirus in NY: Manhattan woman is first confirmed case in state. The New York Times. March 1, 2020. Published March 2, 2020. Accessed January 15, 2021. [URL: https://www.nytimes.com/2020/03/01/ nyregion/new-york-coronvirus-confirmed.html]

4. Governor Cuomo Issues Guidance on Essential Services Under The 'New York State on PAUSE' Executive Order. Accessed January 15, 2021. [URL: https://www.governor.ny.gov/news/governor-cuomo-issues-guidance-essentialservices-under-new-york-state-pause-executive-order]

5. Bonavolontà P, Dell'aversana Orabona G, Abbate V, Vaira LA, Lo Faro C, Petrocelli M, Attanasi F, De Riu G, Iaconetta G, Califano L. The epidemiological analysis of maxillofacial fractures in Italy: The experience of a single tertiary center with 1720 patients. J Craniomaxillofac Surg. 2017 Aug;45(8):1319-1326. [Medline: 28606439] [doi: 10.1016/j.jcms.2017.05.011]

6. Chrcanovic BR. Factors influencing the incidence of maxillofacial fractures. Oral Maxillofac Surg. 2012 Mar;16(1):3-17. [Medline: 21656125] [doi: 10.1007/s10006-011-0280-y]

7. Ludwig DC, Nelson JL, Burke AB, Lang MS, Dillon JK. What Is the Effect of COVID-19-Related Social Distancing on Oral and Maxillofacial Trauma? J Oral Maxillofac Surg. 2021 May;79(5):1091-1097. [Medline: 33421417] [PMC free article: 7735032] [doi: 10.1016/j.joms.2020.12.006]

8. Press SG. What is the Impact of the 2020 Coronavirus Lockdown on Maxillofacial Trauma? J Oral Maxillofac Surg. 2021 Jun;79(6):1329.e1-1329.e5. [Medline: 33609446] [PMC free article: 7825971]

9. Salzano G, Dell'Aversana Orabona G, Audino G, Vaira LA, Trevisiol L, D’Agostino A, Pucci R, Battisti A, Cucurullo M, Ciardiello C, Barca I, Cristofaro MG, De Riu G, Biglioli F, Valentini V, Nocini PF, Califano L. Have There Been any Changes in the Epidemiology and Etiology of Maxillofacial Trauma During the COVID-19 Pandemic? An Italian Multicenter Study. J Craniofac Surg. 2021 Jun 1;32(4):1445-1447. [Medline: $\underline{33229987]}$ [PMC free article: $\underline{8162046]}$ [doi: $10.1097 /$ SCS.0000000000007253] 
10. de Boutray M, Kün-Darbois JD, Sigaux N, Lutz JC, Veyssiere A, Sesque A, Savoldelli C, Dakpe S, Bertin H, Lallemant B, Llobet A, du Cailar M, Lauwers F, Davrou J, Foletti JM. Impact of the COVID-19 lockdown on the epidemiology of maxillofacial trauma activity: a French multicentre comparative study. Int J Oral Maxillofac Surg. 2021 Jun;50(6): 750-755. [Medline: 33172710] [PMC free article: 7648505] [doi: 10.1016/j.ijom.2020.10.005]

11. Szajnoga D, Klimek-Tulwin M, Piekut A. COVID-19 lockdown leads to changes in alcohol consumption patterns. Results from the Polish national survey. J Addict Dis. 2021 Apr-Jun;39(2):215-225. [Medline: 33308059] [doi: $10.1080 / 10550887.2020 .1848247$ ]

12. Chodkiewicz J, Talarowska M, Miniszewska J, Nawrocka N, Bilinski P. Alcohol Consumption Reported during the COVID-19 Pandemic: The Initial Stage. Int J Environ Res Public Health. 2020 Jun 29;17(13):4677. [Medline: 32610613 ] [PMC free article: 7369979] [doi: 10.3390/ijerph17134677]

13. Stuckler D, Basu S, Suhrcke M, Coutts A, McKee M. The public health effect of economic crises and alternative policy responses in Europe: an empirical analysis. Lancet. 2009 Jul 25;374(9686):315-23. [Medline: 19589588] [doi: 10.1016/S0140-6736(09)61124-7]

14. Mazza M, Marano G, Lai C, Janiri L, Sani G. Danger in danger: Interpersonal violence during COVID-19 quarantine. Psychiatry Res. 2020 Jul;289:113046. [Medline: 32387794] [PMC free article: 7190494] [doi: 10.1016/j.psychres.2020.113046]

15. Mucci N, Giorgi G, Roncaioli M, Fiz Perez J, Arcangeli G. The correlation between stress and economic crisis: a systematic review. Neuropsychiatr Dis Treat. 2016 Apr 21;12:983-93. [Medline: 27143898] [PMC free article: 4844458] [doi: $10.2147 /$ NDT.S98525]

16. Olding J, Zisman S, Olding C, Fan K. Penetrating trauma during a global pandemic: Changing patterns in interpersonal violence, self-harm and domestic violence in the Covid-19 outbreak. Surgeon. 2021 Feb;19(1):e9-e13. [Medline: 32826157] [PMC free article: 7392113] [doi: 10.1016/j.surge.2020.07.004]

17. Vishal, Prakash O, Rohit, Prajapati VK, Shahi AK, Khaitan T. Incidence of Maxillofacial Trauma Amid COVID-19: A Comparative Study. J Maxillofac Oral Surg. 2020 Nov 21:1-6. [Medline: 33250599] [PMC free article: 7680068] [doi: 10.1007/s12663-020-01484-y]

18. Rajput K, Sud A, Rees M, Rutka O. Epidemiology of trauma presentations to a major trauma centre in the North West of England during the COVID-19 level 4 lockdown. Eur J Trauma Emerg Surg. 2021 Jun;47(3):631-636. [Medline: 32997167] [PMC free article: 32997167] [doi: 10.1007/s00068-020-01507-w]

19. COVID-19 Regional Metrics Dashboard. COVID-19 Data in New York. Accessed January 18, 2021. [URL: https://forward.ny.gov/covid-19-regional-metrics-dashboard]

20. Chiba H, Lewis M, Benjamin ER, Jakob DA, Liasidis P, Wong MD, Navarrete S, Carreon R, Demetriades D. "Safer at home": The effect of the COVID-19 lockdown on epidemiology, resource utilization, and outcomes at a large urban trauma center. J Trauma Acute Care Surg. 2021 Apr 1;90(4):708-713. [Medline: 33347094] [PMC free article: 7996058] [doi: 10.1097/TA.0000000000003061]

\section{To cite this article:}

Gangwani P, Harris H, Christie M, Mecca K, Barmak B, Kolokythas A.

Aetiology and Epidemiology of Maxillofacial Injuries during the Stay-At-Home Period Due To the COVID-19 Pandemic: a Single Center Study

J Oral Maxillofac Res 2021;12(4):e4

URL: http://www.ejomr.org/JOMR/archives/2021/4/e4/v12n4e4.pdf

doi: $10.5037 /$ jomr.2021.12404

Copyright (C) Gangwani P, Harris H, Christie M, Mecca K, Barmak B, Kolokythas A. Published in the JOURNAL OF ORAL \& MAXILLOFACIAL RESEARCH (http://www.ejomr.org), 31 December 2021.

This is an open-access article, first published in the JOURNAL OF ORAL \& MAXILLOFACIAL RESEARCH, distributed under the terms of the Creative Commons Attribution-Noncommercial-No Derivative Works 3.0 Unported License, which permits unrestricted non-commercial use, distribution, and reproduction in any medium, provided the original work and is properly cited. The copyright, license information and link to the original publication on (http://www.ejomr.org) must be included. 